\title{
INDÚSTRIA DE PROCESSAMENTO DE AMENDOIM
}

\section{PEANUT PROCESSING INDUSTRY}

\author{
Luiz Antônio Mansi - luiz.mansi93@gmail.com \\ Faculdade de Tecnologia de Taquaritinga - Taquaritinga - São Paulo - Brasil \\ Marcos Alberto Claudio Pandolfi - marcos.pandolfi@fatectq.edu.br \\ Faculdade de Tecnologia de Taquaritinga - Taquaritinga - São Paulo - Brasil \\ Eduardo Donizeti Scheler - scheler_1000@hotmail.com \\ Faculdade de Tecnologia de Taquaritinga - Taquaritinga - São Paulo - Brasil
}

DOI: 10.31510/infa.v18i1.1160

Data de submissão: 17/04/2021

Data do aceite: 09/07/2021

Data da publicação: 30/07/2021

\begin{abstract}
RESUMO
O amendoim é uma leguminosa de origem sul-americana, cujo fruto é rico em óleo, proteínas e vitaminas. Sua produção é rentável, sendo que a maior parte produtivo é destinada aos mercados na forma in natura, se destacando como na modalidade cozido e/ou torrado. $\mathrm{O}$ presente artigo tem por finalidade apresentar o cultivo do amendoim como contribuição para o crescimento da agroindústria brasileira. São Paulo se destaca na produção por apresentar fatores edafoclimáticos que favorecem a cultura. $\mathrm{O}$ aumento no consumo dessa leguminosa indica a tendência do crescimento da produção no país. Os principais entraves são a mão de obra cara e maquinários caros, que exigem alto investimento. No presente artigo, a análise financeira apontou total viabilidade da implantação da indústria de processamento de amendoim na cidade de Taquaritinga, interior do estado de São Paulo, sendo que os indicadores econômicos utilizados foram o VPL, TIR, Payback, sendo relevantes para uma boa administração na busca da obtenção de lucro.
\end{abstract}

Palavras-chave: Agronegócio. Matéria-prima. Viabilidade.

\begin{abstract}
Peanut is a legume of South American origin, whose fruit is rich in oil, proteins and vitamins. Its production is profitable, and most of it is destined to the markets in the fresh form, standing out as in the cooked and / or roasted mode. The purpose of this article is to present the cultivation of peanuts as a contribution to the growth of Brazilian agribusiness. São Paulo stands out in production for presenting edaphoclimatic factors that favor culture. The increase in the consumption of this legume indicates the trend of growth in production in the country. The main obstacles are expensive labor and expensive machinery, which require high investment.
\end{abstract}


In the present article, the financial analysis pointed to the total viability of the implantation of the peanut processing industry in the city of Taquaritinga, in the interior of the state of São Paulo, and the economic indicators used were the NPV, TIR, Payback, being relevant for a good administration. in the pursuit of making a profit.

Keywords: Agribusiness. Raw material. Viability.

\section{INTRODUÇÃO}

O amendoim é uma planta herbácea, anual, com ciclo de 90 a 160 dias, atingindo altura de 50 a $60 \mathrm{~cm}$. É uma planta considerada leguminosa originária da América do Sul, o seu fruto é rico em óleo, proteínas e vitaminas (PASSALONGO, 2011).

Segundo a Embrapa (2019) nos últimos 500 anos a planta do amendoim se espalhou pelo mundo, sendo que atualmente o maior produtor é a China. O produto é consumido em boa parte do mundo em diversos pratos de culinária doce e salgada, bem como na indústria. Dados apontam que a produção do amendoim em casca no ano de 2012 chegou a marca de 35.340 .000 toneladas métricas, advinda de uma área de 20.780.000 hectares. No ano de 2011, o Brasil produziu 311.409 toneladas métricas, e em 2012 a marca atingiu 324.178 toneladas, plantados em 101.758 hectares.

No mundo todo, 44.041.913 toneladas de amendoim são produzidas por ano. Os principais países produtores de amendoim são China, com cerca de 16.685 .915 toneladas de volume de produção por ano e a Índia com cerca de 6.857 .000 toneladas de produção anual. O Brasil fica em $11^{\circ}$ lugar em produção, tendo o estado de São Paulo como o principal produtor do país, com cerca de $90 \%$ da produção nacional. Os principais consumidores de amendoim, são os países, China, Índia e Estados Unidos, que juntos totalizaram em 2019, 22.171.719 toneladas de amendoim em grãos em exportações e 622.050 toneladas em importações (ATLASBIG, 2018).

No processamento industrial o amendoim é um produto versátil. Seus subprodutos da extração de seu óleo têm amplo mercado da alimentação animal, trata-se do resíduo denominado torta, que quando refinado, este óleo é utilizado em processos da indústria farmacêutica, cosmética, alimentícia, entre outros. O óleo não refinado é utilizado como combustíveis e lubrificantes. Podendo participar também da produção de sabões especiais para o branqueamento de lã e seda (BARROS; JARDINE, 2008). 
Atualmente o maior consumo é o amendoim in natura, que é distribuído em bares, supermercados, lanchonetes e etc. Sem passar por qualquer processamento, o amendoim é consumido com ou sem casca podendo custar em média de $\mathrm{R} \$ 9,50$ o $\mathrm{kg}$ e $\mathrm{R} \$ 10,50$ o $\mathrm{kg}$, respectivamente.

Segundo o Instituto de Economia Agrícola (IEA), indicam que, em 2020, a produção paulista atingiu 602,9 mil toneladas, fruto do trabalho de realizado em 1.500 propriedades rurais, localizadas principalmente nas regiões de Jaboticabal, Presidente Prudente, Tupã, Marília, Barretos, São José do Rio Preto, Assis, Lins, Catanduva e Ribeirão Preto. No ano passado, quando foram produzidas 469,1 mil toneladas, o produto gerou R $\$ 1,03$ bilhões para o Estado.

No Brasil a colheita mecanizada é utilizada apenas nas lavouras do Estado de São Paulo, onde os produtores têm mais condições para investir em inovações. Nos estados produtores do Nordeste, a maior parte do amendoim produzido vem de pequenos produtores com pouco uso da mecanização, principalmente na colheita (EMBRAPA, 2019).

O presente artigo tem como objetivo analisar a viabilidade de um projeto de abertura de uma indústria processadora de amendoim na cidade de Taquaritinga - SP, através da análise SWOT e demais fatores econômicos e financeiros.

\section{ANÁLISE DE MERCADO DO AMENDOIM}

O amendoim é a quarta oleaginosa de maior cultivo do mundo, ocupando aproximadamente 23 milhões de hectares. No que tange a relevância econômica, o amendoim perde somente para a soja - que ocupa $41,8 \%$ do total mundial -, do algodão - $14,1 \%$ - e da colza - 13,1\% -, participando com cerca de $10 \%$ da população mundial de oleaginosas (FAO, 2011).

De acordo com Santos et al. (2005) no mundo todo são consumidos aproximadamente 8 milhões de toneladas de grãos de amendoim na forma in natura ou industrializada, e entre 15 a 18 milhões na fabricação de óleo comestível.

Segundo a EMBRAPA (2019) em 2012 o Brasil exportou 50.808 toneladas de amendoim sem casca e 400 toneladas de amendoim com casca, rendendo 47.851 milhões de dólares, e 396 mil dólares, respectivamente. O estado de São Paulo é o maior responsável pela produção e exportação de amendoim, sendo que seu percentual de participação na exportação 


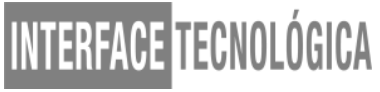

do óleo de amendoim é de $90 \%$. A região paulista de maior destaque na produção de amendoim é a Alta Mogiana, destacando Ribeirão Preto e Jaboticabal, favorecendo a economia local e das cidades vizinhas.

No processamento industrial o amendoim pode ser utilizado na produção de óleo, doces, pasta. No que se refere à exportação do amendoim processado os principais compradores são a Rússia, Ucrânia, Estados Unidos, Chile. E quando se fala em amendoim in natura, grande parte das exportações foram destinados a países como: Rússia, Argélia, Holanda, Polônia, México entre outros (ABICAB, 2018).

A vulnerabilidade do negócio consiste no fato de existir longos períodos de secas no país, no entanto, recentemente um estudo realizado pelo Instituto Agronômico (IAC-APTA) constatou maior produtividade, economia na produção e benefícios ambientais quanto ao plantio de amendoim na palhada de cana-de-açúcar. O IAC constatou aumento de $25 \%$ do conteúdo de água no solo quando da análise, o que beneficia nos períodos de seca, uma vez que a palhada da cana-de-açúcar reduz as perdas de água pela evaporação. (GOMES; GALDINO, 2019)

\section{MATERIAIS E MÉTODOS}

Trata-se de um estudo de caso que analisa a viabilidade para abertura de uma indústria de processamento de amendoim na cidade de Taquaritinga, estado de São Paulo. Para tanto, realizou-se o levantamento bibliográfico com buscas em artigos e materiais publicados em bases de dados eletrônicos acerca da produção e venda de amendoim, e em seguida, realizouse a análise SWOT do empreendimento futuro.

\section{RESULTADOS E DISCUSSÃO}

O amendoim para o processamento será comprado da empresa Coplana, já beneficiado, para diminuir o custo de produção, uma vez que a região de Taquaritinga tem disponibilidade da matéria-prima. A produção da indústria será destinada para jovens, adultos, idosos e crianças, desde que essas pessoas não possuam algum tipo de restrição ao amendoim. No entanto, devido ao seu elevado teor calórico, deve ser consumido com moderação. 


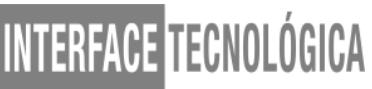

Os principais concorrentes da empresa são outras empresas da cidade e da região que também trabalham com processamento de amendoim. Atualmente uma das grandes dificuldades para a cultura do amendoim é o custo da produção. No entanto, na safra, o valor do produto não deixa margem para erros e/ou prejuízos.

\subsection{Análise SWOT}

\section{Pontos fortes:}

- Concentração alta de matéria-prima no estado de São Paulo

- Redução de custos com transporte da matéria-prima

- Proximidade com o seu mercado, facilita a identificação dos seus desejos e necessidades.

\section{Pontos fracos:}

- Falta de normas técnicas para regulamentar a produção.

- Ausência de ação de marketing.

- Planejamentos estratégico é incipiente.

\section{Oportunidades:}

- Obter o selo da ABICAB para ter maior reconhecimento no mercado interno e externo.

- Inserir os produtos na alimentação escolar.

- Inserir a pasta de amendoim na alimentação de atletas.

\section{Ameaças:}

- O relativo pequeno consumo de derivados no país, já que a demanda é concentrada na sua maioria nos meses de junho e julho.

- Carga Tributária que afeta o preço final.

- Problemas logísticos na entrega do produto final, que interferem no preço, que necessitam ser o mais baixo possível.

\subsection{Processos e instalações industriais}


Dentro do processamento do amendoim, temos dois estágios, o processamento primário e o processamento secundário. No processamento de pasta de amendoim são utilizados quatro equipamentos essenciais; um torrador, um descascador, um triturador e uma máquina envasadora. São diversas etapas que envolvem o processamento do amendoim desde o produto "in natura” até o produto final já processado (Figura 1).

Figura 1 - Processamento Industrial

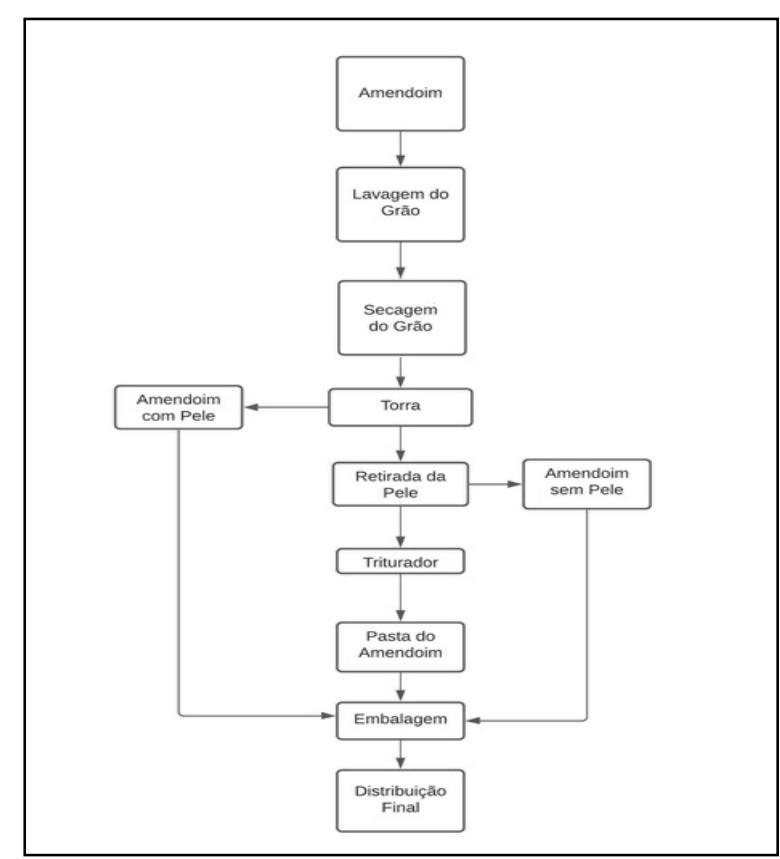

Fonte: Autoria própria

\subsubsection{Norma técnica específica para a produção integrada do amendoim}

A NTE-Amendoim foi formulada com base nas premissas estabelecidas pela Instrução Normativa $\mathrm{n}^{\circ} 27$, de 30 de agosto de 2010. Essa NTE abrange todos os processos relativos a produção agrícola, colheita e pós-colheita do amendoim, conforme diretrizes fixadas pelo Anexo da Portaria ${ }^{\circ}$ 443, de 23 de novembro de 2011, do Instituto Nacional de Metrologia, Qualidade e Tecnologia (Inmetro). Portaria 147/1987 16/07/1987 MINISTÉRIO DA AGRICULTURA, PECUÁRIA E ABASTECIMENTO. GABINETE DO MINISTRO PORTARIA No 147, DE 14 DE JULHO DE 1987. (REVOGADA PELA INSTRUÇÃO NORMATIVA No 32, DE 24 DE AGOSTO DE 2016).

O Ministro de Estado, da Agricultura, no uso das atribuições que lhe confere o $§ 12$, do 
artigo 32, do Decreto $\mathrm{n}^{\mathrm{o}} 82.110$, de 14 de agosto de 1978 , e tendo em vista o disposto na Lei $\mathrm{n}^{\mathrm{o}}$ 6.305 de 15 de dezembro de 1975, resolve:

I - Aprovar a Norma anexa à presente Portaria, assinada pelo Secretário de Serviços Auxiliares de Comercialização e pelo Secretário Nacional de Abastecimento, a ser observada na classificação, embalagem e marcação do amendoim, que se destina à comercialização.

II - Esta Portaria entra em vigor. Na data de sua publicação, revogadas a Portaria no 329 , de 30 de dezembro de 1981, e demais disposições em contrário.

\subsubsection{Produtos e Subprodutos}

Trata-se de um produto de grande versatilidade, sendo que os subprodutos da extração do óleo possuem um mercado amplo na alimentação de animais, utilizando o resíduo denominado como torta. Ainda, quando passado pelo processo de refinamento, pode ser utilizado também na indústria farmacêutica, alimentícia, na produção de cosméticos e demais seguimentos. O óleo sem refinamento pode ser utilizado na produção de sabão, combustíveis e lubrificantes.

A obtenção do óleo da leguminosa é possível de duas formas: prensagem mecânica ou solvente. O primeiro método utiliza prensas contínuas para a retirar o óleo da semente, extraindo-o da torta. Na extração por meio de solvente hexano, cuja derivação é do petróleo, os grãos são triturados para tornar mais fácil a penetração em seu interior.

Quanto ao óleo que se mantém na superfície, utiliza-se a dissolução e a difusão, cujo método é o empregado para o que fica no interior das células intactas. O biodiesel advindo do óleo de amendoim pode ser obtido por meio da reação de transesterificação.

\subsection{Dimensionamento localização e estrutura}

\subsubsection{Macrolocalização}

Os principais polos de cultivos de amendoim do estado de São Paulo são as regiões da alta Mogiana (Ribeirão Preto, Dumont, Jaboticabal e Sertãozinho) e a Alta Paulista (Tupã e Marilia). Cerca de $80 \%$ da colheita é destinada as exportações (a maior parte para os países europeus) e o restante é consumido internamente pelas indústrias de doces. 


\subsubsection{Logística}

Taquaritinga encontra-se situada em um relevante entroncamento rodoviário do interior de São Paulo, sendo composto pelas seguintes rodovias: Brigadeiro Faria Lima [SP-326], que liga Jaboticabal, Matão e Barretos, e Carlos Tonanni [SP-333], que liga Jaboticabal a Ribeirão Preto. Outras rodovias que dão acesso ao município, quais sejam: Rodovia José Pizarro [SP305]: Jaboticabal - Monte Alto; Rodovia Nemésio Cadetti [SP-333]: Jaboticabal - Taquaritinga; Rodovia Cunha Bueno [SP-253]: Jaboticabal - Luís Antônio.

\subsubsection{Mão de obra}

A mão de obra será advinda da cidade local e das cidades vizinhas: Guariba, Monte Alto, Taquaritinga, Pitangueiras, Taiaçu, Taiúva, entre outras, haja vista que oferecem serviços nos setores de educação superior, transportes, saúde, comércios e serviços.

\subsubsection{Política}

- Garantir a produção de alimentos seguros ao consumo de seus clientes e consumidores, atendendo os seus requisitos;

- Cumprir de forma adequada os requisitos legais e regulamentares aplicáveis;

- Comunicar de forma eficaz com as partes interessadas;

- Conscientizar os colaboradores, mantendo a cultura e o compromisso do trabalho de segurança dos alimentos.

\subsubsection{Localização da Agroindústria}

A localização da agroindústria está situada na cidade de Jaboticabal na rodovia Faria Lima, assim facilitando sua logística no recebimento do amendoim "in natura" e na distribuição do produto final. Seu planejamento engloba todo o abastecimento da região, assim como seu ponto estratégico de matéria prima em abundancia devido a região rica em cana-deaçúcar.

A agroindústria além de produzir a pasta de amendoim, tem como produtos o amendoim com e sem casca. A área de produção conta com todos os equipamentos necessários para o 
processamento, armazenamento e a distribuição do produto (Tabela 1). A capacidade de produção da agroindústria é de 145 unidades de cada produto por dia, sendo que sua área de instalações é de $600 \mathrm{~m}^{2}$.

Tabela 1 - Custos com equipamentos, utensílios e acessórios

\begin{tabular}{|c|c|c|c|c|c|}
\hline \multicolumn{6}{|c|}{ EQUIPAMENTOS / UTENSILIOS / ACESSÓRIOS } \\
\hline Item & Quant & Descriçao & Valor Unit & \multicolumn{2}{|c|}{ Valor total } \\
\hline 1 & 1 & Máquina de limpeza e secagem de grãos & $\mathrm{R} \$ 12.499,00$ & $\mathrm{R} \$$ & $12.499,00$ \\
\hline 2 & 1 & Descascador de amendoim & $\mathrm{R} \$ \quad 3.599,00$ & $\mathrm{R} \$$ & $3.599,00$ \\
\hline 3 & 1 & Moinho para pasta de amendoim & $\mathrm{R} \$ 28.699,00$ & $\mathrm{R} \$$ & $28.699,00$ \\
\hline 4 & 1 & Torrador de grãos & $\mathrm{R} \$ \quad 8.350,00$ & $\mathrm{R} \$$ & $8.350,00$ \\
\hline 5 & 1 & Envasadora & $\mathrm{R} \$ \quad 6.650,00$ & $\mathrm{R} \$$ & $6.650,00$ \\
\hline 6 & 1 & Seladora de embalagens & $\mathrm{R} \$ \quad 1.000,00$ & $\mathrm{R} \$$ & $1.000,00$ \\
\hline 7 & 1 & Rotuladora de embalagens & $\mathrm{R} \$ \quad 850,00$ & $\mathrm{R} \$$ & 850,00 \\
\hline 8 & & & & & - \\
\hline 9 & & & & & - \\
\hline 10 & & & & & - \\
\hline 11 & & & & & - \\
\hline 12 & & & & & - \\
\hline 13 & & & & & - \\
\hline 14 & & & & & - \\
\hline 15 & & & & & - \\
\hline \multirow[t]{2}{*}{16} & & & & & - \\
\hline & & SUBTOTAL 2 & & RS & $1.647,00$ \\
\hline
\end{tabular}

TOTAL INVESTIMENTOS

R\$ 61.647,00

Fonte: Autoria própria

Quanto aos custos fixos, os mesmos totalizam R\$ $254.087,52$ no período de um ano (Tabela 2).

Tabela 2 - Custos fixos

\begin{tabular}{|c|c|c|c|c|}
\hline \multicolumn{5}{|c|}{ CUSTOS FIXOS } \\
\hline Item & Descrição & & & Valor / ano \\
\hline 1 & Aluguel & $\mathrm{R} \$$ & $6.500,00$ & $78.000,00$ \\
\hline 2 & Salários & $\mathrm{R} \$$ & $6.000,00$ & $72.000,00$ \\
\hline 3 & Serviços escritório & $\mathrm{R} \$$ & 0,00 & 0,00 \\
\hline 4 & Alvará & $\mathrm{R} \$$ & 12,50 & 150,00 \\
\hline 5 & Bombeiro & $\mathrm{R} \$$ & 3,36 & 40,32 \\
\hline 6 & Simples Nacional & $\mathrm{R} \$$ & $4.458,10$ & $53.497,20$ \\
\hline 7 & FGTS & $\mathrm{R} \$$ & $1.045,00$ & $12.540,00$ \\
\hline 8 & Telefone & $\mathrm{R} \$$ & 45,00 & 540,00 \\
\hline 9 & Internet & $\mathrm{R} \$$ & 70,00 & 840,00 \\
\hline
\end{tabular}


WTEREFGEETECNOLOGGCA

\begin{tabular}{|l|l|rr|c|}
10 & Energia & $\mathrm{R} \$$ & 700,00 & $8.400,00$ \\
\hline 11 & Água & $\mathrm{R} \$$ & 500,00 & $6.000,00$ \\
\hline 12 & Limpeza & $\mathrm{R} \$$ & $1.350,00$ & $18.000,00$ \\
\hline 13 & Manutenção & $\mathrm{R} \$$ & 340,00 & $4.080,00$ \\
\hline \multicolumn{2}{|r|}{ TOTAL } & \multicolumn{2}{|c|}{ R\$ 21.023,96 } & R\$ 254.087,52 \\
\hline
\end{tabular}

Fonte: Autoria própria

Os custos variáveis, por sua vez, totalizam a quantia anual de R\$1.716.543,60 (Tabela $3)$.

Tabela 3 - Custos variáveis

\begin{tabular}{|c|c|c|c|c|c|}
\hline Item & Descriçao & Qtdade / mês & Valor unit. & Valor Total / mês & Valor Total / ano \\
\hline 1 & Matéria-prima & 16575 & 7,60 & $125.970,00$ & $1.511 .640,00$ \\
\hline 2 & Combustível & 70 & 2,79 & 195,30 & $2.343,60$ \\
\hline 3 & Embalagens-pote & 13000 & 0,98 & $12.740,00$ & $152.880,00$ \\
\hline 4 & Rótulo & 13000 & 0,11 & $1.430,00$ & $17.160,00$ \\
\hline 5 & Materiais de escritório & 1 & 210,00 & 210,00 & $2.520,00$ \\
\hline 6 & Etiqueta & 100 & 25,00 & $2.500,00$ & $30.000,00$ \\
\hline 7 & & & & - & - \\
\hline 8 & & & & - & - \\
\hline 9 & & & & - & - \\
\hline 10 & & & & - & - \\
\hline 11 & & & & - & - \\
\hline & & TOTAL & & R\$ 143.045,30 & $\mathrm{R} \$ 1.716 .543,60$ \\
\hline
\end{tabular}

Fonte: Autoria própria

Tabela 4 - Estimativa Receita

\begin{tabular}{|c|c|c|c|c|c|c|c|c|}
\hline \multicolumn{9}{|c|}{ ESTIMATIVA DE PRODUÇÃO / RECEITA } \\
\hline \multirow{2}{*}{$\frac{\text { Item }}{1}$} & \multirow{2}{*}{$\begin{array}{l}\text { Descrição / item } \\
\text { Pasta de amendoim }\end{array}$} & \multirow{2}{*}{$\begin{array}{c}\text { Qtdade / mês } \\
4.350 \\
\end{array}$} & \multicolumn{2}{|c|}{ Preço de venda } & \multicolumn{2}{|c|}{ Receita Mensal } & \multicolumn{2}{|c|}{ Receita anual } \\
\hline & & & $\mathrm{R} \$$ & 14,10 & $\mathrm{R} \$$ & $61.335,00$ & $\mathrm{R} \$$ & $736.020,00$ \\
\hline 2 & Amendoim com pele & 4.350 & $\mathrm{R} \$$ & 11,50 & $\mathrm{R} \$$ & $50.025,00$ & $\mathrm{R} \$$ & $600.300,00$ \\
\hline 3 & Amendoim sem pele & 4.350 & $\mathrm{R} \$$ & 12,60 & $\mathrm{R} \$$ & $54.810,00$ & $\mathrm{R} \$$ & $657.720,00$ \\
\hline 4 & & & & & & 0,00 & & 0,00 \\
\hline 5 & & & & & & 0,00 & & 0,00 \\
\hline 6 & & & & & & 0,00 & & 0,00 \\
\hline 7 & & & & & & 0,00 & & 0,00 \\
\hline
\end{tabular}

R\$ 166.170,00

R\$ 1.994.040,00 
WWTEPFAG TEECNOLOGGCA

RECEITA LÍQUIDA

R\$ 2.100,74

R\$ 23.408,88

Fonte: Autoria própria

Tabela 5 - Fluxo de Caixa

\begin{tabular}{|c|c|c|c|c|c|c|}
\hline & \multicolumn{2}{|c|}{ ANO 0} & ANO 1 & ANO 2 & ANO 3 & ANO 4 \\
\hline \multicolumn{2}{|l|}{ FC SIMPLES } & $-\mathrm{R} \$ 61.647,00$ & $\begin{array}{l}\mathrm{R} \$ \\
23.408,88\end{array}$ & $\begin{array}{l}\mathrm{R} \$ \\
23.408,88\end{array}$ & $\begin{array}{l}\mathrm{R} \$ \\
23.408,88\end{array}$ & $\begin{array}{l}\mathrm{R} \$ \\
23.408,88\end{array}$ \\
\hline \multicolumn{2}{|l|}{ FC ACUMULADO } & $-\mathrm{R} \$ 61.647,00$ & $\begin{array}{l}\mathrm{R} \$ \\
38.238,12\end{array}$ & $\begin{array}{l}-\mathrm{R} \$ \\
14.829,24\end{array}$ & $\begin{array}{l}\mathrm{R} \$ \\
8.579,64\end{array}$ & $\begin{array}{l}\mathrm{R} \$ \\
31.988,52\end{array}$ \\
\hline \multicolumn{2}{|l|}{$\begin{array}{l}\text { FC } \\
\text { DESCONTADO }\end{array}$} & $-\mathrm{R} \$ 61.647,00$ & $\begin{array}{l}\mathrm{R} \$ \\
22.294,17\end{array}$ & $\begin{array}{l}\mathrm{R} \$ \\
21.232,54\end{array}$ & $\begin{array}{l}\mathrm{R} \$ \\
20.221,47\end{array}$ & $\begin{array}{l}\mathrm{R} \$ \\
19.258,54\end{array}$ \\
\hline \multicolumn{2}{|l|}{ FC ACUM/DESC. } & $-\mathrm{R} \$ 61.647,00$ & $\begin{array}{l}\mathrm{R} \$ \\
39.352,83 \\
\end{array}$ & $\begin{array}{l}-\mathrm{R} \$ \\
18.120,28 \\
\end{array}$ & $\begin{array}{l}\mathrm{R} \$ \\
2.101,19 \\
\end{array}$ & $\begin{array}{l}\mathrm{R} \$ \\
21.359,73 \\
\end{array}$ \\
\hline ANO 5 & \multicolumn{2}{|c|}{ ANO 6} & NO 7 & ANO 8 & ANO 9 & ANO 10 \\
\hline $\begin{array}{l}\mathrm{R} \$ \\
23.408,88\end{array}$ & \multicolumn{2}{|c|}{$\begin{array}{l}\mathrm{R} \$ \\
23.408,88\end{array}$} & $\begin{array}{l}\mathrm{R} \$ \\
23.408,88\end{array}$ & $\begin{array}{l}\mathrm{R} \$ \\
23.408,88\end{array}$ & $\begin{array}{l}\mathrm{R} \$ \\
23.408,88\end{array}$ & $\begin{array}{l}\mathrm{R} \$ \\
23.408,88\end{array}$ \\
\hline $\begin{array}{l}\mathrm{R} \$ \\
55.397,40\end{array}$ & \multicolumn{2}{|c|}{$\begin{array}{l}\mathrm{R} \$ \\
78.806,28\end{array}$} & $\begin{array}{l}\mathrm{R} \$ \\
102.215,16\end{array}$ & $\begin{array}{l}\mathrm{R} \$ \\
125.624,04\end{array}$ & $\begin{array}{l}\mathrm{R} \$ \\
149.032,92\end{array}$ & $\begin{array}{l}\mathrm{R} \$ \\
172.441,80\end{array}$ \\
\hline $\begin{array}{l}\mathrm{R} \$ \\
18.341,47\end{array}$ & \multicolumn{2}{|c|}{$\begin{array}{l}\mathrm{R} \$ \\
17.468,07\end{array}$} & $\begin{array}{l}\mathrm{R} \$ \\
16.636,25\end{array}$ & $\begin{array}{l}\mathrm{R} \$ \\
15.844,05\end{array}$ & $\begin{array}{l}\mathrm{R} \$ \\
15.089,57\end{array}$ & $\begin{array}{l}\mathrm{R} \$ \\
14.371,02\end{array}$ \\
\hline $\begin{array}{l}\mathrm{R} \$ \\
39.701,20\end{array}$ & \multicolumn{2}{|c|}{$\begin{array}{l}\mathrm{R} \$ \\
57.169,27\end{array}$} & $\begin{array}{l}\mathrm{R} \$ \\
73.805,52\end{array}$ & $\begin{array}{l}\mathrm{R} \$ \\
89.649,57\end{array}$ & $\begin{array}{l}\mathrm{R} \$ \\
104.739,14\end{array}$ & $\begin{array}{l}\mathrm{R} \$ \\
119.110,17\end{array}$ \\
\hline \multicolumn{2}{|l|}{ TMA } & \multicolumn{2}{|c|}{$5,0 \%$} & \begin{tabular}{l|l} 
& $\mathbf{0 , 0 5 0}$ \\
\end{tabular} & & \\
\hline
\end{tabular}

PAYBACK

SIMPLES

2,63

PAYBACK

DESC.

VPL

R\$ 119.110,17

TIR

\section{$30 \%$}

\begin{tabular}{|l|r|}
\hline Investimento total & $61.647,00$ \\
\hline Custos fixos totais / período & $254.087,52$ \\
\hline Custos variáveis totais / período & $1.716 .543,60$ \\
\hline Receita líquida total / período & $23.408,88$ \\
\hline
\end{tabular}

Fonte: Autoria própria

Com base nos dados levantados pela análise, não há como negar a viabilidade da abertura de uma indústria de processamento de amendoim, haja vista que todos os fatores 
contribuem para a efetividade do negócio, especialmente pelo retorno de investimento ser rápido e levando em consideração a localidade e os fatores climáticos do país.

\section{CONCLUSÃO}

Com base no levantamento de dados realizado no presente artigo, o amendoim se mostra tendencioso a crescer tanto em consumo como exportação no Brasil, sendo que a maior oferta de alimentos produzidos à base de amendoim encontra-se concentrada no estado de São Paulo, com destaque para a Alta Mogiana. Da mesma forma, há uma relevante necessidade de controle efetivo das condições de colheita no campo, estocagem e transporte do produto.

Com base na análise da viabilidade financeira, por meio dos indicadores financeiros VPL, TIR e Payback, o projeto da indústria apresentado mostrou totalmente viável. Portanto, entende-se que em uma projeção estimada de 10 anos, o retorno do investimento realizado será em cerca de 2 anos e 7 meses.

Ademais, importa mencionar que com a implantação da indústria de processamento de amendoim, poderão ser produzidos três tipos de produtos: o amendoim com e sem casca e a pasta de amendoim, fazendo com que o negócio seja mais rentável e atenda um público maior do mercado.

\section{REFERÊNCIAS}

ABICAB NEWS, 2012 - Associação Brasileira da Indústria de Chocolates, Amendoim e Balas. Disponível em: <https://www.abicab.org.br>. Acesso em: 28 set. 2020.

ATLASBIG, 2018. Principais produtores de amendoim. Disponível em: $<$ https://www.atlasbig.com/pt-br/paises-por-producao-de-amendoim $>$. Acesso em: 24 set. 2020 .

BARROS, T, D; JARDINE, J, G. Semente oleaginosas para produção de biodiesel. Agência Embrapa de Informação Tecnológica. 2008. Disponível em: $<$ http://www.agencia.cnptia.embrapa.br/gestor/agroenergia/arvore/CONT000fbl23vn002wx5e o0sawqe3ex35v9p.html>. Acesso em 24 set. 2020.

EMBRAPA, 2019. Sistema de Produção de Amendoim. Disponível em: $<$ https://www.spo.cnptia.embrapa.br/conteudo?p_p_id=conteudoportlet_WAR_sistemasdepro ducaolf6_1galceportlet\&p_p_lifecycle $=0 \& p \_p \_s t a t e=$ normal $\& p \_p \_$mode $=v i e w \& p \_p \_c o l i d$ =column-1\&p_p_col_count $=1 \& p \_r \_p \_-76293187$ sistemaProducaoId $=3803 \& p \_r$ p_996514994_topicoId=3455>. Acesso em 24 set. 2020. 
GOMES, Carla; GALDINO, Mônica. IAC transfere conhecimento em plantio do amendoim em palhada da cana. Apta-SP, 2019. Disponível em: $<$ http://www.apta.sp.gov.br/noticias/iactransfere-conhecimento-em-plantio-do-amendoim-em-palhada-da-cana $>$. Acesso em: 16 abr. 2021.

INSTITUTO DE ECONOMIA AGRÍCOLA, 2018. Amendoim: da renovação de canaviais ao mercado externo. Disponível em: $<$ http://www.iea.sp.gov.br/out/TerTexto.php?codTexto=14508>. Acesso em: 24 set. 2020.

PASSALONGO, D, G, 2011. A cultura do amendoim. Disponível em: $<$ https://www.sabernarede.com.br/a-cultura-do-amendoim/>. Acesso em: 24 set. 2020.

SANTOS, R.C.; VALE, L.V.; SILVA, R.R.F.; ALMEIDA, R.P.; ALMEIDA, V.M.R.A. Recomendações técnicas para cultivo de amendoim precoce no período das águas. Circular técnica 20, Campina Grande: Embrapa Algodão, 1996. 